\title{
Atmospheric Weathering of Historic Monuments and Their Related Conservation Issues
}

\author{
Emine N. Caner-Salt1k \\ Graduate Program in Conservation, Department of Architecture, \\ Archaeometry Program, Graduate School of Natural and Applied Sciences, \\ Middle East Technical University (METU), Ankara \\ E-mail: canersal@yahoo.com.tr
}

\begin{abstract}
Atmospheric environment affects the materials of historic monuments and their structure starting from the time of their construction. Daily and seasonal changes in temperature and humidity, wind, snow and rainfall, soluble salts carried by water, biological agents, pollutant gases and particulate matter are some of the agents in atmospheric environment that introduce weathering by physical, chemical and biological processes in the materials of the monuments such as natural building stones, bricks, mortars and plasters, mud brick etc. The weathering processes need to be well diagnosed by identification of main mechanisms of decay and major responsible agents, degree and depth of deterioration expressed with measurable parameters of physical, physicomechanical properties, and micro structural changes together with their distribution on the monument. Success of conservation treatments strongly depend on those diagnostic studies and compatibility of the treatments with the deteriorated and relatively sound parts of the historic materials. Current approach to materials conservation is to be able to make minimum intervention to historic material by targeting the conservation treatment to the deteriorated area for the purpose of controlling the deterioration factors and achieving compatible and durable conservation of historical material. In this presentation, two examples of diagnostic research and conservation treatments based on and guided by the diagnostic results are summarized concerning historic stone monuments exposed to atmospheric environment since more than two thousand years. The first example is on the marble walls of Temple of Augustus in Ankara exposed to polluted urban atmosphere. The second example is on the limestone statues of Nemrut Mount Monument in Adiyaman-Turkey, exposed to rural atmosphere with harsh climatic conditions. Finally, a brief discussion on current research issues related to historic materials conservation in atmospheric environment is made.
\end{abstract}

\section{Introduction}

Materials of historic monuments and their structure are affected by the atmospheric environment they live in since the time of their construction. Daily and seasonal changes in temperature and humidity, wind, snow and rainfall, soluble salts carried by water, biological agents, pollutant gases and particulate matter are some of those agents in atmospheric environment that introduce some changesby physical, chemical and biological processes.In time, those weathering processes cause considerable changes in microstructure of stone, such as increase in porosity, decrease in mechanical properties, quite a number of changes in chemical composition etc. starting from exterior surfaces towards interiors of the stone. Those changes are also visible by change in color, detachments as scales and flakes, crack formation, material loss as powdering, granular disintegration, outbursts etc. Diagnostic analyses aim at finding out the main process of decay and its responsible decay agents as well as the degree and extent of decay on the material and its distribution on the monument. They serve as a guide for the selection and development of conservation treatments. The approach in diagnostic analyses of monuments is similar to the diagnostic analyses in medical field without which no curative treatment can be done, although human life is very short compared to the life of monuments many of which surviving since 
centuries. It should not be forgotten that conservation treatment should not endanger the life of the monument and its survival capacity but help its survival in its aesthetic unity.

\section{Temple of Augustus}

The Temple of Augustus is one of the oldest standing monuments in Ankara from Roman period. The Roman Baths and a part of Roman city walls are situated not very far from the Temple.The Temple of Augustusis not only a standing monument from Roman Period but also a written document. It carries on its marble stone walls the only original text of Emperor Augustus in Greek and Latin letters. It is essential to preserve that monument in its present condition with its historic and aesthetic integrity. In order to be able to do that, one had to clarify the point about what it was going wrong with the monument.

That work is a diagnostic study to determine what the main decay agents are, and how much damage they have produced on the monument. Those questions were investigatedby the use several analytical tools with minimum representative sampling (1).

The air pollution damage was drastic in the years starting from 1970 up to mid-eighties, while the population in the city had rapid growth, coal was being used in central heating and traffic started being heavy. Climatic conditions of Ankara atmosphere with high average relative humidity values in winter months and during the nights through the year even in summer times favored adsorption of both nitrogen oxides and sulphur dioxide on allstone surfaces. Those gases are able to react with the materials of the monument at high relative humidity conditions thus causing great damages on historic monuments. The pollutants reaching the materials surfaces as particulate matter carried by air currents or gases are called dry deposition mechanisms while the pollutants in acid rain directly wetting and washing the surfaces of materials are called wet deposition mechanisms.Nitrogen oxides from traffic are known to act as catalysts in the reactions of sulphur dioxide with the calcareous stones during the conversion of calcite to gypsum. Damage is known to be more extensive on the monuments constructed of calcareous building stones such as marble, limestone and travertine.

A project was started for the diagnosis of the current materials and structural problems of Temple of Augustus and development of its conservation treatments (2-6).

The visual forms of the decay on the monument are observed as grey, black, yellow, brown colour change and depositions, detachments as scales, detachments as granular disintegration and
In this study, diagnostic studies and conservation treatments research about two important monuments in Turkey, namely marbles of Temple of Augustus and limestone statues of Nemrut Mount Monument are summarised and discussed.

powdering, material loss by loss of scales, grains, and powders. Photogrammetric drawings of the Temple were used for mapping those main decay forms observed on the Temple. Forms and degrees of the weathering at the monument do not show an equal distribution. The decay forms range between severe decays and light decays. Those differences were thought to be due to differences of the microclimatic conditions on the surfaces of the stone,different wetting conditions with rain water since there was no roof on the monument for its protection from rainwater,and probably the different types of marbles used for the construction of the monument. IR thermography studies on the surfaces of the monument have proved to be a useful non destructive investigation to reveal the state of deterioration together with the USV measurements

Mineralogical and micro structural properties of the marble samples from the Temple were investigated by optical microscopic analyses of cross sections and thin sections, SEM-EDX analyses of cross sections, XRD and FTIR analyses of powdered samples. The marbles of Temple of Augustus were medium to coarse grained. The sizes were 20-200 microns for medium grains, and up to $1 \mathrm{~mm}$ for coarse grains. It was found that the marbles of the walls having latin inscription consist of calcite minerals together with dolomite minerals while the marbles of the walls having greek inscription consisted of calcite. SEM-EDX analyses showed that the main mineral calcite was transformed to gypsum mineral $\left(\mathrm{CaSO}_{4} \cdot 2 \mathrm{H}_{2} \mathrm{O}\right)$. XRD and FTIR analyses confirmed that the main decay product is gypsum together with biominerals such as calcium oxalate.That.has proved the presence of biodeterioration on the surface of Temple of Augustus together with gypsum formation as a result of air pollution. Biological activity and its distribution was further investigatedby qualitative and quantitative analyses with fluorescein diacetate (FDA) (6).

The formation of gypsum was not only present on the surface but also distributed towards the interiors of the marble structure. Transformation of calcite to gypsum included volume expansion.The analyses indicated that the characteristic compact structure of marbles was changed by deterioration. The grains were separated from one another and spaces of various sizes were produced in between. The pore sizes varied from capillary size of few microns to a few hundreds of microns. The pore 
structure of the deteriorated marble had to be taken into account in the conservation treatments.

Then it comes the solutions about how to control and stop the main decay agents, and the description of treatments to be applied to the decayed materials based on the current conservation methods whether those are applicable or adaptable to that case or a new treatment is necessary to be developed.

Since gypsum is soluble in water $(\sim 2.2 \mathrm{~g} / \mathrm{l})$, the Temple needed a roof to protect it from wetting by rain penetration.Calcium oxalate minerals are quite insoluble . their solubility product is much less than calcite.Preesence of calcium oxalates, although itwas not in the form of a continuous layer but in a scattered formation, decreased the solubility of gypsum to some extent. The $\mathrm{SO}_{2}$ pollution in Ankara is now diminished since the use of coal is stopped and natural gas is being used instead.Traffic is tried to be eliminated at least in the vicinity of the monument.

It was necessary to strengthen the weak marble by consolidation and sticking the scales with compatible repair mortars each of which required the laboratory and in situ research on development of suitable methods. Here, marble consolidation treatments will be mentioned (5).

Aim of marble consolidation treatments was to improve the properties of decayed stone to such an extent that a compatible relationship is formed with the decayed and the relatively non-decayed parts after the treatment. It was aimed to form a structure with similar physico-mechanical properties and compatible with the chemical and mineralogical properties of the stone.. In other words, deteriorated, less deteriorated and not deteriorated parts of the marble should be connected to get a

\section{Views from the Temple of Augustus}

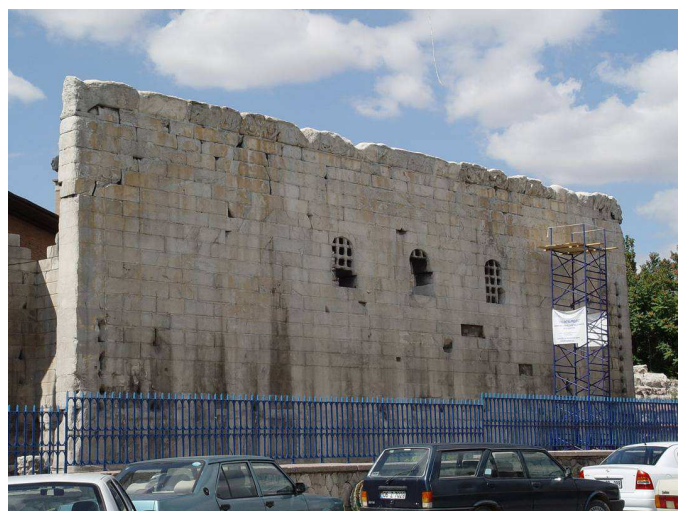

compatible and durable unit. For those purposes some consolidation treatments were performed based on the information gained on the types and degree of decay of the marbles in the Temple of Augustus. It was avoided to use synthetic polymers of any sort since they form a new structure in decayed stone that differ a lot in its response to the changes of atmospheric temperature and humidity and separate itself from the rest of the stone in a short period of time.

In this research, consolidation treatments were developed by the preparation of nanodispersive solutions of $\mathrm{Ca}(\mathrm{OH})_{2}$ in ethyl alcohol. Efficient growth of calcium carbonate crystals in the pores and capillaries by incorporating them with the present calcite network of marble were tried to be achieved with nanodispersive solutions of calcium hydroxide. Precipitation of micritic calcite was observed in the fine cracks of marble that were formed as a result of consolidation treatment. After the consolidation treatments the ultrasonic velocity values of the marbles have increased and their porosities have decreased.

The method was found to be successful, however the different nanodispersive solutions needed to be prepared in accordance to the locations with different types and degrees of deterioration. For this reason, samples with different deterioration problems were studied in detail with several analytical techniques before and after treatments.

Long term performance of consolidation treatments continue to be monitored by nondestructive tests of ultrasonic pulse velocity measurements and quantitative infrared thermography imaging in situ and in laboratory.

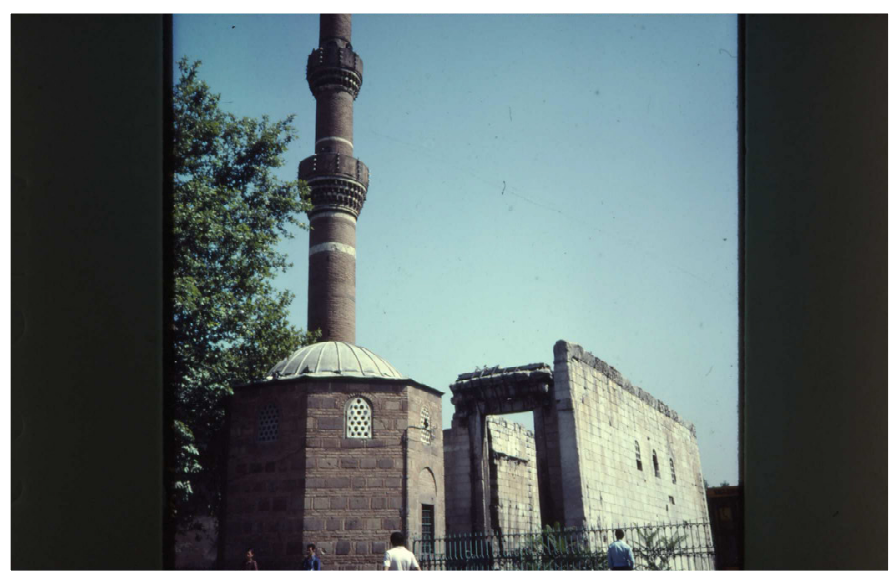

\section{Nemrut Mount Monument}

Nemrut Mount Monument is one of the most spectacular archaeological sites situated on top of a high Mountain, more than two thousand meters high having very harsh climatic conditions with strong winds, covered with snow during almost half of the 
year. Monument is a temple with giant statues of Gods and King Antiochos around his Tumulus, built in around two thousand years ago during Kommagene Kingdom. The site is in World Heritage List since 1986.Nemrut Mount belong to the large Midyat Formations of Eocene age, precipitated in marine environment. Limestone statues were selected and carved from the limestone of the mountain itself. They are karstic limestone with visible and invisible karstic veins. Quite a number of decay forms are visually seen on the limestone statues. Abundance of decay forms as fragmental disintegration through some karstic veins of limestone, colored biological depositions and pitting were observed at the site, both on limestone statues and geological limestone deposits. In this study, the causes and mechanism of fragmental disintegration formation, and extent of biological weathering was examined in order to figure out what type of conservation treatments were to be done (7-8). Examinations were done on the small fragments of samples that were lost from the statues and on the samples from the nearby geological formations that showed similar deterioration forms with the limestone statues. Samples from geological formations were cut to $5 \mathrm{~cm}$ cubes and were used for artificial weathering by salt crystallization in the laboratory. Progress of stone deterioration was examined in the laboratory by salt crystallization tests. Unlike most other techniques the sodium sulphate crystallization test was a comparative test to obtain data for monitoring and discovering the weak zones of limestone.Both naturally and artificially decayed limestone were examined for their physical, physico-mechanical and microstructural properties. Physical and physicomechanical properties were examined by bulk density, effective porosity, and ultrasonic velocity measurements (8). Microstructural properties of deteriorated limestones were observed by examination of cross sections with SEM-EDX, by analyses of thin sections with optical microscopy and by examination of powdered samples scraped from exterior surfaces, crack surfaces and interiors of the stone using XRD and FTIR analyses. Distribution of biological activity was determined by qualitative and quantitative analyses with FDA (6). The petrographical analysis of limestones indicated that the limestones had micritic and microsparitic particles and they bonded with sparitic calcite crystals. Some submicroscopic opaque minerals as iron oxides and fossils were also observed in thin sections of limestones. Physico-mechanical studies indicated that weathered limestone samples taken from the monument had bulk density $\sim 2.67 \mathrm{~g} / \mathrm{cm}^{3}$ and porosity $\sim 0.8 \%$. Samples collected from geological formations in the vicinity were a bit denser and had slightly lower porosity. Some karstic zones of limestone were found to be preferred sites of decay for the start of surface dissolution and for the formation and widening of cracks. Presence of clay minerals kaolinite, illite, chlorite in those decay zones, iron oxides that move through those zones, as well as biological activity that found those sites favorable and started to live in there were found to be closely related to fragmental disintegration phenomena. Swelling of chlorites and increase in their swelling by weathering were expected. The swelling characteristics of kaolinite and illite were considered to be very small. However, they may take part in deterioration by several other mechanisms. The mobility of clay minerals in the aqueous media caused the transportation of the clay minerals in the fine capillaries of the stone. The role of clay minerals in deterioration by other mechanisms such as ion exchange capacity, acting as reservoirs for nucleation of new crystals etc. might also be important in the growth of cracks.

The most important deterioration type observed in limestones was fragmental disintegration that proceeded through micro cracks in the structure of limestone and enlarged in changing atmospheric conditions. The changes in atmospheric conditions introduced wetting and drying cycles of the clay minerals and iron oxides in the micro cracks. At the same time, calcium carbonate dissolution and recrystallization reactions took place in the cracks of the limestone. Some clay minerals accumulated from outside and settlement of micobiological growth and increase in biological activity accelerated fragmental disintegration process. To prevent the widening of the cracks and fragmental disintegration, it was necessary to decrease the activity of clay minerals and control the wetting and drying in the micro cracks. Nano dispersive $\mathrm{Ca}(\mathrm{OH})_{2}$ solutions were used to decrease the activity (cation exchange capacity) of the clay minerals in the cracks of limestones. After treatment with nano dispersive $\mathrm{Ca}(\mathrm{OH})_{2}$ solutions, a considerable decrease was observed in the cation exchange capacity of the clay minerals. The decrease in clay minerals activity was measured by methylene blue absorption method (8). Decreasing the activity of clay minerals and controlling their swelling by the use of nano dispersive $\mathrm{Ca}(\mathrm{OH})_{2}$ solutions was expected to control the widening of the cracks and loss by fragmental disintegration. The control of wetting and drying in the cracks were done by further treatments of the cracks with nano dispersive $\mathrm{Ca}(\mathrm{OH})_{2}$ solutions that would form a calcite network in the cracks similar to the structure of the original limestones. Carbonation of nano dispersive $\mathrm{Ca}(\mathrm{OH})_{2}$ solutions injected in the cracks were accelerated by providing high relative humidity and higher $\mathrm{CO}_{2}$ concentrations in the treatment areas by using temporary covers. Filling of cracks with calcite network would prevent rain penetration through 
them. Therefore, the study was focused on the preparation of variable concentrations of nano dispersive $\mathrm{Ca}(\mathrm{OH})_{2}$ solutions with some additives that were able to penetrate through the deep cracks in

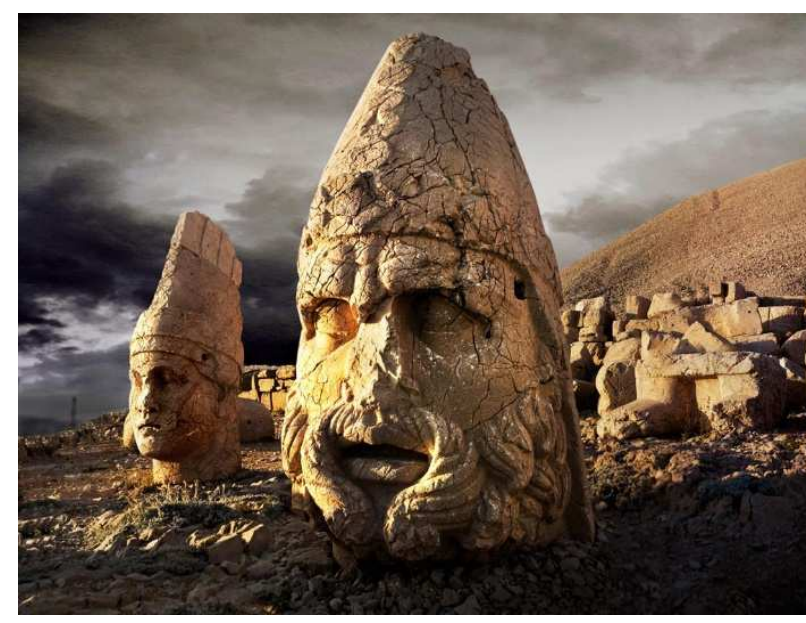

A View from the Nemrut Mount Monument (7)

\section{Research topics and trends in conservation of historic building materials exposed to atmospheric environment}

Recent research topics in conservation science concerning materials of historic monuments exposed to atmospheric environment are now concentrated on the development of treatments with nano dispersive solutions and repair materials including nano powder additives. Compatibility and durability criteria for the treatments and improvements of the methods in their evaluation are topics of high interest.

Many methods of conservation are stopped being used due to their damaging effects that developed in time and due to their irreversibility and incompatibility.

While studies on the conservation treatments develop, the need for the diagnostic studies that describe in detail, the degree and the process of deterioration in historic material is increased. Better the diagnosis, better the chance for adjustment of the proper dose of the treatment that serves the purpose. Advances in analytical techniques contribute a lot to the advances in diagnosis and treatments; small representative samples now become sufficient enough to do the identification of decay problems.

Researchers are in need of describing the interaction of new treatments with the historic material in time. Non-destructive techniques are developing to be used in diagnostic studies as well as in monitoring the efficiency of conservation treatments. Quantitative Infrared Thermography (QIRT) and Ultrasonic velocity measurements (USV) are very useful to follow the success of conservation treatments in time and measure their compatibility and durability with the original structure. the limestone (8-9). Pilot treatment areas at the site are monitored to verify the longterm success of the treatments.

European standards on the investigation and conservation of historic materials and structures are being developed (CH-EN).

Conservation studies of historic monuments involve multidisciplinary work. That fact presents some coordination and management problems to be overcome. Another important topic is to fill the gap between conservation science research results and current conservation practice.

Importance of research laboratories specialized on conservation of historic monuments is increased. Research laboratories on historic monuments can only serve their purpose if well-educated conservation scientists are responsible and in charge of conservation issues.Planning of a diagnostic and conservation research, its execution, its monitoring need to be in the responsibility of highly qualified researchers who have Ph.D on conservation science issues. Multidisciplinary nature of research team is the key to the success. Scientists from the fields of chemistry, physics, biology, construction science, materials science, archaeometry, engineers and architects who are knowledgeable on functional systems of buildings, all who are further qualified by $\mathrm{Ph} . \mathrm{D}$ in conservation science are badly needed. All those are common European assets and are being supported by a number of different collaborations.

\section{References}

1. E. N. Caner, H. Göktürk, A. G. Türkmenoğlu, G. Eseller,. Effects of air pollution on the monuments of Ankara, Case Study: Temple of Augustus. Durability of Building Materials, 5, 463-473. (1988)

2. E. H. Göktürk, M. B. Al-Badawi, S. Aygün, E. N. Caner, "Determination of Nitrate and Nitrite by Ion Selective Electrodes in Relation to Gypsum Formation on Some Travertine Buildings in Polluted Atmosphere of Ankara" Intern. J. Environ.Anal. Chem. 40 47-57. (1990).

3. E. N. Caner, H.Böke, "Occurence of Calcium Oxalates on Marble Monuments in Anatolia" Proceedings of International Symposium on; The Oxalate Films: Origin and Significance in the Conservation of Works of Art;G. Alessandrini Ed., Centro CNR "GINO BOZZA" Milano, 299-307, (1989)

4. Temple of Augustus Conservation Project: Control of Stone Deterioration, Structural Maintanence and Site Presentation.Coordinator: Prof. Dr. Emine N. Caner-Saltık. METU, World Monument Fund. Ministry of Culture: General Directorate of Cultural Heritage and Museums. (2006) 
5.Development of new methods of conservation for marble in archaeological sites and monuments: A study to develop combined treatments for marble conservation using nanoparticlesand biomineralization, Turkish-French University Cooperation Project 2004-2005, METU-MCL and LRMH France. Turkish Team Coordinator: Prof. Dr. Emine N. Caner-Saltık, (2005)

6. M. C. Üstünkaya, Biological Decay and Its Control by Biomineralisation in Calcareous Stones, Unpublished Master Thesis, METU. Ankara, (2008)

7. Commagene-Nemrut Conservation and Development Program: Program for Preparing a Management Plan, Materials and Structural Conservation of Nemrut Mountain, Tumulus and Its Monuments. Coordinators: Prof. Dr. Emine N.
Caner-Saltık \& Assoc. Prof. Dr. Neriman Şahin Güçhan. METU, Ministry of Culture: General Directorate of Cultural Heritage and Museums. (2010)

8. E. Caner, E. N. Caner-Saltık, G. Orial, J. Mertz, "Deterioration Mechanisms of Historic Limestone and Development Of Its Conservation Treatments With NanodispersiveCa(OH)2 Solutions" In: 8th International Symposium on the Conservation of Monuments in the Mediterranean Basin: Monument Damage Hazards \& Rehabilitation Technologies, Eds: M. Koui, F. Zezza, P. Koutsoukos, Technical Chamber of Greece, Athens, V.3, 54-72.( 2013)

9. P. Lopez-Arce, L. Gomez-Villalba, S. MartinezRamirez, M. Alvarez de Buergo, Powder Technol., 205, 